\title{
Teasing Out the
}

\section{Answers}

All month long, students heard reminders to support the mathletes at their upcoming meet. Even though CHAPS was known for its high-caliber academics, all non-sport activities had to beg for supporters besides parents to show up to events. As the math event got closer and closer, the halls buzzed with chatter about the upcoming basketball game against their rivals from St. Mark's Academy.

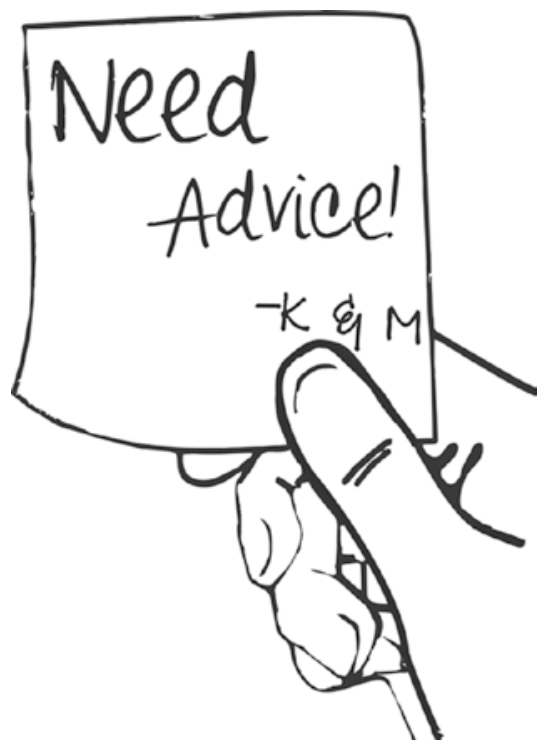

(C) Melissa A. Borza and CA 2017

M. A. Borza, Fashion Figures, DOI 10.1007/978-I-4842-2274-4_7 
On Tuesday, Missy noticed another yellow note stuck on her locker. "Need advice. K + M," Missy read. Missy scratched her head, at first thinking " $K+M$ " might be a code to crack; then she realized that it was a message from Kim and Megan. She exchanged some books from her backpack and locker and headed around the corner to look for them. Missy passed by Paula who directed her to Ms. Jameson's math classroom. When Missy got to them, Kim and Megan were sitting cross-legged by the door reviewing a long page of math problems. Missy had gone through elementary school with the two girls and had stayed friends with them even though they had different interests.

"Hey," she said by way of greeting, and the two girls looked up.

“Oh! Missy! Please, please join the math club!" Megan said and pulled Missy down by her hand into a crouched position. "We really need more girls, and we could use your elite skills."

Missy blushed and nearly toppled over. "Whoa," she said and righted herself into a more stable position. "Your note said that you needed advice. How can I help? And don't say by joining the math club!”

"Well," Kim said, exchanging looks with Megan, "we think someone is acting like a bully on the math team. We don't want to get anyone in trouble, but we don't want to be bullied or watch others be bullied either."

“OMG!” Missy said."That's awful! Why do you think I can help?”

Kim looked down at her hands and fidgeted with her pencil."I just remember that you used to be bullied ... I mean, I don't want to make you feel bad, but I thought maybe you could tell us how you managed it and maybe what to do."

Missy let go of Megan's hand and leaned in closer to the girls. She suddenly felt dizzy and on the verge of tears. "I guess you're right. I used to be called 'Missy-Math-Maker.' It started with one boy calling me that and then others picked it up and repeated it and repeated it. And, then it kind of stuck." Missy paused, thinking back to just last year and elementary school. Missy wrapped her arms together holding her stomach, which suddenly felt tight, as she remembered how upset she had been by all the teasing.

"It was really hard for me. It made me feel bad about myself just for being a good student. I know that's weird, but ...," Missy's voice trailed off, she did not want to admit that she still struggled with those memories and feelings.

"We remember," Megan said. "I felt terrible for you."

"Is someone calling you names?" Missy asked, turning the topic around so she didn't feel so exposed. "You have to tell a teacher or a guidance counselor or the principal!" Missy exclaimed.

"I know it. Right?" Megan said. "That's what I said we should do, too," she looked at Kim who nodded in agreement. "It's just that we don't want to get anyone on the team in trouble." 
"If you're talking about the math team, then you should start by talking to Ms. Jameson. I know she will listen and help you," Missy advised. "You know CHAPS has a zero tolerance policy against bullying, right? If you tell her, I know she can solve the problem."

The first bell rang and the girls gathered their books and papers and stood up. "Thanks, Missy!" Megan said."I do feel better."

"Yes," Kim added."I knew you could help us!"

The three girls exchanged quick hugs and then dashed to their first-period classes. Missy was glad she could help, though she felt sad remembering all the teasing that she had lived through.

\section{FASHION HACK: T-SHIRT GROCERY SACK HOW-TO}

1. Find an old adult-sized extra-large t-shirt with a great graphic on it.

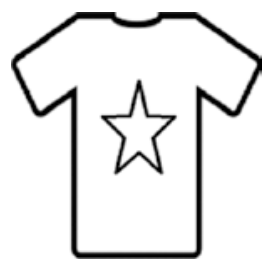

2. Cut handles by cutting off the arms. Then cut a deep U-shape around the front and back of the neckline.

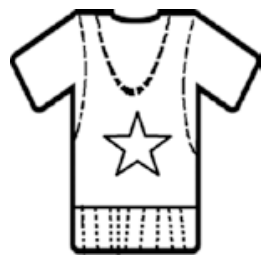

3. Cut fringe along the bottom of the t-shirt and tie the fringe into knots along the edge.

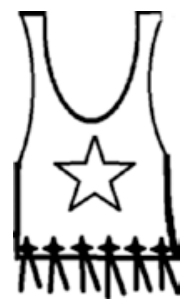

